\title{
OPTIMALISASI PRODUKSI SEMI REFINED CARAGINAN (SRC) DARI RUMPUT LAUT( Eucheuma cottonii)
}

\section{[OPTIMIZATION OF SEMI REFINED CARRAGENAN (SRC) PRODUCTION FROM SEAWEEDS (Eucheuma cottonii)]}

\author{
Moh Rizal $^{1^{\star}}$, Mappiratu ${ }^{1}$, Abd. Rahman Razak ${ }^{1}$ \\ 1) Jurusan Kimia FMIPA Universitas Tadulako, Palu
}

Diterima 30 Oktober 2015, Disetujui 29 Desember 2015

\begin{abstract}
The investigation about the optimization of SRC Production (semi refined caraginan) from Eucheuma cottonii has beendone. The study aim to find whether or not there is interaction beetween consentration $\mathrm{KOH}$ and cooking time on rendamen and SRC purity degree and to find at which consentration $\mathrm{KOH}$ and cooking time yield the highest SRC Purity degree. It was done by applying completely randomized design (CRD) i. e factorial design. It was consist of 2 factors ( consentration $\mathrm{KOH}$ and cooking time ). Each factors consist of 3 levels and all of experiments where done in duplo, so the total there ware 18 experiments. The result showed that The highest Rendaman and the highset degree of piyurity were obsained at consentration $\mathrm{KOH}$ and cooking time were $8 \%$ and 60 minutes respectively. The result were 33.83 and $59.243 \%$ accordingly
\end{abstract}

Keywords : Eucheuma cottonii, Extraction Semi Refined Carrageenan, $\mathrm{KOH}$ concentration, Long time of cooking

\begin{abstract}
ABSTRAK
Telah dilakukan penelitian optimalisasi produksi semi refined caraginan (SRC) dari rumput Laut Eucheuma cottonii. Penelitian ini bertujuan untuk mengetahui interaksi antara konsentrasi $\mathrm{KOH}$ dengan waktu pemasakan terhadap rendemen dan derajat kemurnian semi refined caraginan dan mengetahui pengaruh konsentrasi $\mathrm{KOH}$ dan waktu pemasakan terhadap rendemen dan derajat kemurnian Semi Refined Caraginan. Penelitian dirancang menggunakan Rancangan Acak Lengkap (RAL) pola perlakuan faktorial, yang terdiri atas dua faktor, konsentrasi $\mathrm{KOH}$ dan lama pemanasan, masing - masing faktor terdiri atas 3 taraf yang diulang 2 kali sehingga terdapat 18 unit percobaan.Parameter yang diamati rendemen dan derajat kemurnian SRC. Hasil yang diperoleh menunjukkan terdapat interaksi antara konsentrasi $\mathrm{KOH}$ dengan lama pemasakan. Konsentrasi $\mathrm{KO}$ dan lama pemasakan berpengaruh terhadap rendemen dan derajat kemurnian SRC. Rendemen tertinggi (33,83\%) ditemukan pada penggunaan konsentrasi $\mathrm{KOH} 8 \%$ dan lama pemanasan 60 menit. Demikian pula derajat kemurnian SRC tertinggi $(59,23 \%)$ terdapat pada penggunaan konsentrasi $\mathrm{KOH} 8 \%$ dan lama pemasakan 60 menit.
\end{abstract}

Kata kunci : Eucheuma cottonii,Semi Refined Caraginan, Konsentrasi KOH, Lama Pemasakan. 


\section{LATAR BELAKANG}

Rumput laut termasuk salah satu jenis tanaman perairan yang saat ini banyak dibudidayakan oleh masyarakat Indonesia termasuk masyarakat Sulawesi Tengah. Rumput laut mempunyai prospek untuk dikembangkan terutama rumput laut jenis Eucheuma cottoni. Pada tahun 2009, Sulawesi Tengah termasuk penghasil rumput laut terbesar ketiga di Indonesia setelah Nusa Tenggara Barat (NTB) dan Sulawesi Selatan (Zatnika dan Istini, 2007 dalam Serdiati dan Widiastuti, 2010). Pada tahun 2014, produksi rumput laut jenis Eucheuma cottonii mencapai 80.000 ton kering, naik sekitar $100 \%$ dari tahun sebelumnya, yakni 39.400 ton kering pada tahun 2013. Pemerintah Daerah Sulawesi Tengah, sejak 2007 terus berusaha meningkatkan produksi rumput laut yang direncanakan pada tahun 2011, Sulawesi Tengah menjadi provinsi Rumput Laut di Indonesia dan usaha menuju ke arah tersebut terus dilakukan hingga saat ini (Afraeni, 2015).

Rumput laut jenis Eucheuma cottonii selain memiliki daya tahan terhadap penyakit, juga mengandung karaginan kelompok kappa karaginan dengan kandungan yang relatif tinggi, yakni sekitar $50 \%$ atas dasar berat kering. Kappa karaginan bernilai ekonomi tinggi, yakni 10 sampai 20 kali harga rumput laut. Atas dasar tersebut kandungan karaginan rumput laut Eucheuma cottonii dijadikan sebagai faktor utama penentu mutu, dalam arti makin tinggi kandungan karaginan makin tinggi mutu rumput laut Eucheuma cottonii (Samsuar, 2006).

Karaginan adalah zat aditif alami yang banyak dimanfaatkan dalam berbagai industri, terutama industri makanan dan kosmetika. Semi Refined Caraginan (SRC) adalah salah satu produk karaginan dengan tingkat kemurnian lebih rendah dibandingkan dengan refined caraginan. SRC mengandung sejumlah kecil selulosa yang ikut mengendap bersama karraginan. Semi Refined Caraginan (SRC) secara komersial diproduksi dari rumput laut jenis Eucheuma cottonii melalui proses pemanasan menggunakan larutan alkali Kalium Hidroksida (KOH) (Minghou, 2015).

Pembuatan Semi Refined Caraginan (SRC) dipengaruhi oleh berbagai factor antara lain konsentrasi $\mathrm{KOH}$, lama pemanasan dan suhu pemanasan serta rasio larutan $\mathrm{KOH}$ terhadap rumput laut (Mappiratu, 2009; Dewi et al., 2012; Norma dan Nazarifah, 2003). Peningkatan konsentrasi $\mathrm{KOH}$ sangat mungkin menurunkan lama pemasakan dan suhu pemasakan. Penelitian bertujuan untuk mengetahui konsentrasi $\mathrm{KOH}$ dan lama pemasakan yang menghasilkan SRC dengan rendemen dan derajat kemurnian yang tinggi.

\section{METODE PENELITIAN}

\section{Bahan dan Peralatan}

Bahan dasar yang digunakan ialah rumput laut Eucheumma cottonii yang 
diperoleh dari Desa Lalombi Kecamatan

Banawa Selatan Kabupaten Donggala

Provinsi Sulawesi Tengah, dan bahan pendukung lainnya terdiri dari Kalium Hidroksida, Etanol 95 \% dan Aquadest.

Peralatan yang digunakan mencakup neraca analitik, oven, penangas air, cawan petri, evaporator, desikator, vakum, batang pengaduk, gelas ukur dan alat - alat gelas yang umum digunakan dalam Laboratorium Kimia.

\section{Prosedur Penelitian}

Rumput Laut kering sebanyak $20 \mathrm{~g}$ dimasukkan ke dalam $500 \mathrm{ml}$ gelas kimia dan ditambahkan $300 \mathrm{ml}$ larutan $\mathrm{KOH}$, konsentrasi masing-masing 6\%, 8\%, dan $10 \%$. Dipanaskan pada suhu $100^{\circ} \mathrm{C}$ dengan waktu pemanasan masingmasing 30 menit, 45 menit dan 60 menit, setelah itu disaring. Semi Refined Caraginan (SRC) yang diperoleh dipotong - potong hingga mencapai ukuran 3 - 4 $\mathrm{cm}$, kemudian dikeringkan dioven selama 48 jam pada suhu $85^{\circ} \mathrm{C}$, ditimbang beratnya dan ditentukan rendemennya menggunakan persamaan berikut

$$
\text { Rendemen }=\frac{\text { Berat SRC }}{\text { Berat Rumput Laut }} \times 100 \%
$$

SRC yang dihasilkan dalam bentuk chip ditimbang sebanyak $1 \mathrm{~g}$, kemudian ditambah dengan aquadest sebanyak 55 $\mathrm{ml}$, dan setelah itu campuran dipanaskan selama 3 jam pada suhu $100^{\circ} \mathrm{C}$. Campuran selanjutnya disaring dengan kain saring. Filtrat yang dihasilkan dipekatkan sampai $50 \%$, dan hasil ekstrak pekatan didinginkan kemudian dicampur dengan etanol $95 \%$ dengan rasio $3: 1$ atas dasar $\mathrm{v} / \mathrm{v}$, diaduk dan dibiarkan selama 24 jam. Endapan (karaginan) yang terbentuk disaring, kemudian dikeringkan dalam oven pada suhu $100^{\circ} \mathrm{C}$ selama 3 jam, kemudian ditimbang dan ditentukan derajat kemurnian SRC menggunakan persamaan berikut.

$$
\text { Derajat Kemurnian SRC }=\frac{\text { Berat karaginan }}{\text { Berat SRC }} \times 100 \%
$$

\section{HASIL DAN PEMBAHASAN}

\section{Rendemen SRC}

Rendemen Semi Refined Caraginan yang dihasilkan dari rumput laut Eucheuma cottonii dipengaruhi oleh berbagai faktor, antara lain faktor konsentrasi $\mathrm{KOH}$, lama waktu pemasakan, suhu, dan faktor ukuran partikel rumput laut.Untuk mendapatkan informasi tentang pengaruh konsentrasi $\mathrm{KOH}$ dan waktu masak serta interaksinya, diterapkan konsentrasi $\mathrm{KOH}$ dengan 3 taraf dan lama waktu pemasakan dengan 3 taraf. Hasil yang diperoleh (Tabel 1) menunjukkan rendemen SRC tertinggi $(33,83 \%)$ ditemukan pada penggunaan konsentrasi kalium hidroksida $8 \%$ dan waktu pemasakan 60 menit, dan rendemen semi refined caraginan terendah terdapat pada penggunaan konsentrasi kalium hidroksida $6 \%$ dan waktu pemasakan 30 menit.

Pada Tabel 1 memperlihatkan rendemen SRC meningkat dengan 
meningkatnya waktu pemasakan. Hal tersebut teramati lebih baik pada Gambar 1. Pada gambar tersebut memberikan indikasi tentang adanya peluang peningkatan rendemen pada peningkatan waktu pemasakan.

Tabel 1 Hasil Penentuan Rendemen SRC pada berbagai konsentrasi $\mathrm{KOH}$ dan lama pemasakan

\begin{tabular}{|c|c|c|c|}
\hline \multirow{2}{*}{$\begin{array}{c}\text { Konsentrasi } \\
\text { KOH (\%) }\end{array}$} & \multicolumn{3}{|c|}{$\begin{array}{c}\text { Rendemen SRC pada } \\
\text { berbagai waktu masak } \\
\text { (menit) }\end{array}$} \\
\cline { 2 - 4 } & $\mathbf{3 0}$ & $\mathbf{4 5}$ & $\mathbf{6 0}$ \\
\hline 6 & 12.47 & 17.66 & 23.28 \\
\hline 8 & 27.41 & 28.46 & 33.83 \\
\hline 10 & 21.45 & 26.22 & 30.58 \\
\hline
\end{tabular}

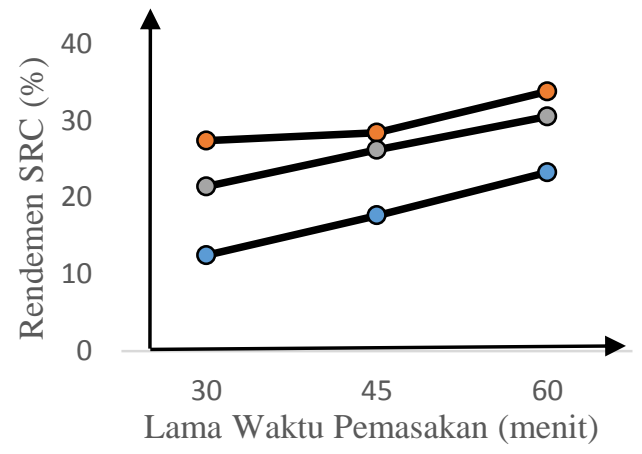

$-\infty \begin{array}{lll}-\infty & -\infty\end{array}$

Gambar 1 Kurva perubahan Rendemen terhadap waktu masak pada berbagai konsentrasi $\mathrm{KOH}$

Hal yang berbeda untuk konsentrasi $\mathrm{KOH}$. Peningkatan konsentrasi $\mathrm{KOH}$ tidak menyebabkan peningkatan rendemen secara linier, akan tetapi pada perubahannya mengikuti garis kurva parabola, dimana konsentrasi optimum terdapat pada konsentrasi $\mathrm{KOH} 8 \%$ (Gambar 2). Dengan demikian peningkatan waktu pemasakan pada konsentrasi $\mathrm{KOH} 8 \%$ sangat mungkin meningkatkan rendemen SRC. Pada penelitian ini, rendemen SRC mencapai optimum pada penggunaan konsentrasi $\mathrm{KOH} 8 \%$. Pada konsentrasi tersebut dihasilkan rendemen sebesar $33.83 \%$.

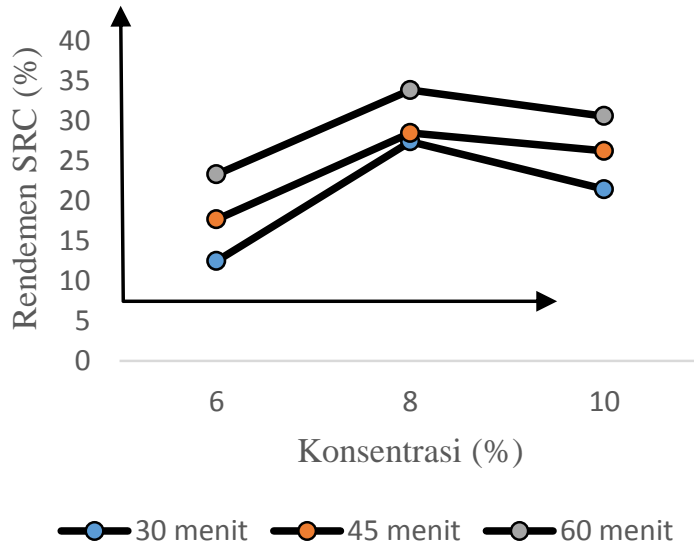

Gambar 2 Kurva perubahan rendemen terhadap konsentrasi $\mathrm{KOH}$ pada berbagai waktu masak.

Temuan rendemen SRC pada penggunaan konsentrasi $\mathrm{KOH} \quad 8 \quad \%$ dengan waktu masak 60 menit relative lebih tinggi dibandingkan dengan temuan Faidhliyah (2010) dan Samsuar (2006). Faidhliyah (2010) menemukan rendemen SRC $27 \%$ pada pemasakan rumput laut Eucheuma cottonii selama 3 jam. Samsuar (2006) menemukan rendemen SRC $29.63 \%$ pada penggunaan $\mathrm{KOH} 9 \%$ dengan waktu pemasakan 4 jam.

\section{Derajat kemurnian Semi Refined} Carraginan dari berbagai konsentrasi $\mathrm{KOH}$ dan lama pemasakan

Derajat kemurnian atau persentase karaginan dalam SRC selain dipengaruhi oleh konsentrasi $\mathrm{KOH}$ dan waktu masak, 
juga dipengaruhi oleh tingkat kepekatan ekstrak dan rasio ekstrak / etanol, serta rasio pelarut terhadap rumput laut atau SRC. Kepekatan ekstrak dan rasio ekstrak letanol berhubungan dengan pengendapan karaginan, sedangkan rasio pelarut terhadap SRC berhubungan dengan jumlah karaginan terekstrak.

Hasil analisis derajat kemurnian pada berbagai konsentrasi $\mathrm{KOH}$ dan lama waktu pemasakan (Tabel 2 ) menunjukkan derajat kemurnian tertinggi (59.24 \%) ditemukan pada penggunaan $\mathrm{KOH}$ dengan konsentrasi $8 \%$ dan dengan waktu masak 60 menit, dan derajat kemurnian terendah $(22.78 \%)$ terdapat pada peggunaan konsentrasi $\mathrm{KOH} 6 \%$ dan waktu masak 30 menit. Derajat kemurnian SRC sejalan dengan rendemen yang meningkat dengan meningkatnya waktu masak, dan mengikuti garis kurva parabola pada peningkatan konsentrasi $\mathrm{KOH}$ untuk semua waktu masak.

Tabel 2 Hasil Penentuan Derajat kemurnian SRC pada berbagai konsentrasi $\mathrm{KOH}$ dan lama pemasakan

\begin{tabular}{|c|c|c|c|}
\hline \multirow{2}{*}{$\begin{array}{c}\text { Konsentrasi } \\
\text { KOH (\%) }\end{array}$} & \multicolumn{3}{|c|}{$\begin{array}{c}\text { Derajat Kemurnian SRC } \\
\text { pada berbagai waktu } \\
\text { masak (menit) }\end{array}$} \\
\cline { 2 - 4 } & $\mathbf{3 0}$ & $\mathbf{4 5}$ & $\mathbf{6 0}$ \\
\hline 6 & 22.78 & 27.47 & 29.76 \\
\hline 8 & 53.41 & 57.19 & 59.24 \\
\hline 10 & 31.04 & 40.04 & 42.1 \\
\hline
\end{tabular}

Dengan mengacu pada pola yang sama antara rendemen dan derajat kemurnian, maka terdapat praduga penurunan rendemen pada peningkatan konsentrasi $\mathrm{KOH}$ di atas dan dibawah $8 \%$ disebabkan karena adanya komponen dalam rumput laut yang terlarut ketika dilakukan pemasakan. Komponen tersebut salah satu diantaranya adalah karaginan. Analisis statistik memberikan keterangan terdapat interaksi antara waktu masak dengan konsentrasi $\mathrm{KOH}$ terhadap rendemen dan derajat kemurnian SRC yang dihasilkan. Bana (2014) melaporkan bahwa derajat kemurnian SRC pada kondisi optimum (pemekatan $50 \%$, rasio ekstrak / etanol 1 : 3) sebesar $51.1 \%$, sedangkan Aprilia (2006) hanya menghasilkan derajat kemurnian $35.29 \%$. Perbedaan tersebut disebabkan karena perbedaan mutu rumput laut yang dijadikan sebagai bahan baku

\section{KESIMPULAN}

Berdasarkan hasil penelitian dapat disimpulkan bahwa:

1. Terdapat interaksi antara Konsentrasi $\mathrm{KOH}$ dan waktu masak terhadap rendemen dan derajat kemurnian Semi Refined Carraginan (SRC)

2. Rendemen berbanding lurus dengan derajat kemurnian Semi Refined Carraginan (SRC) pada semua konsentrasi $\mathrm{KOH}$ dan waktu masak yang diterapkan

3. Rendemen Semi Refined Caraginan (SRC) tertinggi $(33,83 \%)$ dan Derajat kemurnian SRC tertinggi ( 59,24\%) terdapat pada penggunaan konsentrasi $\mathrm{KOH} 8 \%$ dan waktu pemasakan 60 menit 


\section{DAFTAR PUSTAKA}

Afraeni N. 2015. Pengembangan Sistem Penguatan Industri Rumput Laut Eucheuma cottonii di Kabupaten Morowali. [Tesis]. Yogyakarta: Program Pascasarjana Fakultas Teknik, Universitas Gadjah Mada. (etd.repository.ugm.ac.id/downloa dfile/88474/.../S2-2015-342675title.pdf). Diakses pada tanggal 24 Oktober 2015.

Aprilia I A., 2006, Ekstraksi Karaginan Dari Rumput Laut Jenis Eucheuma cottonii. Proseding Seminar Nasional Teknik Kimia Indonesia. Palembang 19-20 Juli 2006. hal BBTP 24-1- BBTP24-6.

Dewi, E.N; Darmanto Y.S., Ambariyanto. 2012. Characterization and quality of semi refined carrageenan (SRC) products from different coastal water based on fourier transform infrared technique. J. Coastal Development. 14:25 - 31 .

Bana EAH. 2014. Kajian Metode Gravimetri Dalam Analisis Kadar Karaginan Rumput Laut (Eucheuma cottonii). [Skripsi]. Palu: Jurusan Kimia Fakultas Matematika dan IImu Pengetahuan Alam UNTAD.

Faidhliyah Nilna M. (2010) Tinjauan Kualitas Karaginan dari Euchema Cottoni pada Penggunaan Pelarut dan Waktu Ekstraksi yang Berbeda pada Metode Ekstraksi. Proseding Seminar Nasional Teknik Kimia Surabaya.
Mappiratu. 2009, Kajian Teknologi Pengolahan Karaginan Dari Rumput Laut Eucheuma cottonii Skala Rumah Tangga, Jurnal Media Litbang Sulteng. 2(1): 01-06.

Minghou, J., TT 2015. Processing and Extraction of phycocolloids. Institute of Oceanology, Academia Sinica Qingdao, China. (http: //www.fao.org/docrep/field/003/AB7 28E/AB728E09.htm.) Diakses pada tanggal 12 April 2015.

Normah dan I. Nasarifah. 2003. Production of semi-refined carrageenan from locally available red seaweed, Eucheuma cottonii on a laboratory scale. J. Trop. Agric. And Fd. Sc. 31(2) : $207-$ 213

Samsuar. 2006. Karakteristik karaginan Rumput laut Eucheuma cottonii Pada berbagai Umur panen, Konsentrasi $\mathrm{KOH}$ dan Lama Ekstraksi. [Tesis]. Bogor: Sekolah Pasca Sarjana Institut Pertanian Bogor.

Serdiati N, Widiastuti IM. 2010. Pertumbuhan dan Produksi Rumput Laut Eucheuma cottonii pada Kedalaman Penanaman yang Berbeda. Media Litbang Sulteng. III (1) : $21-26$. 